\title{
Rosiglitazone attenuates lipopolysaccharide-induced depressive-like behavior and cognitive deficits in mice
}

\author{
Iris Juliana Viotto Stupp ${ }^{1,2}$, Eguiberto Bernardes Fraga-Junior ${ }^{1}$, Diego Luiz Doneda ${ }^{1}$, Eric Hirokazu Taniguti ${ }^{1}$, Yago Silva Ferreira ${ }^{1}$, Beatriz \\ Schmidt Dal Berto ${ }^{2}$, Cláudia Bonadiman de Lima ${ }^{2}$, Carlos Henrique Rocha-Junior ${ }^{2}$, Eliângela de Lima ${ }^{1}$, Fabrício Rios Santos ${ }^{1}$, Ziliani da \\ Silva Buss ${ }^{2}$ and Samuel Vandresen-Filho ${ }^{1 *}$ \\ ${ }^{1}$ Laboratório de Fisiologia, Departamento de Ciências Básicas em Saúde, Faculdade de Medicina, Universidade Federal de Mato Grosso, Boa Esperança,78060-900, \\ Cuiabá, MT, Brazil \\ ${ }^{2}$ Laboratório de Imunologia, Departamento de Ciências Básicas em Saúde, Faculdade de Medicina, Universidade Federal de Mato Grosso, Boa Esperança,78060-900, \\ Cuiabá, MT, Brazil
}

\begin{abstract}
Previous studies have shown that neuroinflammation induced by lipopolysaccharide (LPS) cause depressive-like behavior and cognitive deficits in rodents. A number of studies have demonstrated that rosiglitazone, an agonist of peroxisome proliferator-activated receptor gamma (PPAR- $\gamma$ ), exerts neuroprotective effects in experimental models of neurological and psychiatric diseases. In this study, we aimed to evaluate the putative protective effects of rosiglitazone treatment on LPS-induced depressive-like behavior and cognitive deficits in mice. Animals were treated with rosiglitazone ( $5 \mathrm{mg} / \mathrm{kg}$, v.o.) one hour before LPS (0.5mg/ $\mathrm{kg}$, i.p.) administration. One day after LPS infusion, mice were submitted to the behavioral tests and, thereafter, biochemical determinations were performed. Rosiglitazone prevented an LPS-induced increase in the duration of immobility in tail suspension and forced swim tests, indicating an antidepressant-like effect. Rosiglitazone significantly prevented the decrease in spontaneous alternations induced by LPS in the Y-maze test. In the inhibitory avoidance task, LPS decreased the step-down latencies in the test session, which were ameliorated by rosilgitazone treatment. In the open field test, no changes in ambulation were observed. Rosiglitazone prevented LPS-induced increase in TNF- $\alpha$ and reduction of brain-derived neurotrophic factor (BDNF) levels in the hippocampus. Rosiglitazone also improved LPS-induced increase in lipid peroxidation and the reduction of glutathione levels in the hippocampus. Our findings suggest that rosiglitazone may possess neuroprotective effects against LPS-induced depressive-like behavior and cognitive deficits through attenuation of neuroinflammation, oxidative damage, and normalization of BDNF levels.
\end{abstract}

\section{Introduction}

Depression is a common and debilitating mental disease estimated to affect 350 million people of all ages across the world [1]. Core symptoms of depression include low mood, anhedonia, cognitive dysfunction, loss of interest, loss of energy, suicidal ideation and disturbed sleep or appetite [2]. Conventional treatment of depression is based on drugs that modulate monoaminergic transmission [3]. This traditional pharmacotherapy presents delayed onset of clinical action, provides a complete remission in only $50 \%$ of individuals and is associated with several side effects that make it difficult for patients adherence to the treatment [4]. Thus, there is a need to develop new highly effective and rapid-acting therapeutic strategies to treat depressive disorders.

Despite several pathophysiological hypotheses, the mechanisms underlying depression are not completely understood. However, previous studies have implicated an interaction between inflammation and depression [5,6]. Increased serum levels of pro-inflammatory cytokines have been demonstrated in depressed patients [7]. In mice, systemic administration of the bacterial endotoxin, lipopolysaccharide (LPS), has been shown to induce behavioral alterations such as depressive-like behavior and cognitive impairment [8,9]. LPS induces brain expression of proinflammatory cytokines such as tumor necrosis factor- $\alpha$ (TNF- $\alpha$ ), promotes oxidative stress and decreases brainderived neurotrophic factor (BDNF) levels $[10,11]$. These neurotoxic effects have been implicated in LPS-induced depressive-like behavior and memory impairments [12,13].

The ligand-activated peroxisome proliferator-activated receptor $\gamma$ (PPAR- $\gamma)$ is a member of the nuclear receptor superfamily that plays an important role in glucose homeostasis and lipid metabolism [14]. Rosiglitazone, a thiazolidinedione drug, is an agonist of PPAR- $\gamma$ used for the treatment of type II diabetes [15]. Besides, rosiglitazone is known to exert neuroprotective effects in models of Alzheimer's disease, Parkinson's disease, Huntington's disease, epilepsy, stroke and traumatic brain injury [16,17]. Moreover, the antidepressant-like effect of rosilgitazone in mice has been demonstrated in an experimental model $[18,19]$. The neuroprotective effects of rosiglitazone have been attributed to attenuation of neuroinflammation and mitochondrial dysfunction [20].

*Correspondence to: Samuel Vandresen Filho, Laboratório de Fisiologia, Departamento de Ciências Básicas em Saúde, Faculdade de Medicina, Universidade Federal de Mato Grosso Boa Esperança, 78060-900 Cuiabá, MT, Brasil, E-mail: samuelvandresen@yahoo.com.br

Key words: peroxisome proliferator-activated receptor gamma; inflammation; depression; memory; brain-derived neurotrophic factor; oxidative stress

Received: November 28, 2018; Accepted: December 10, 2018; Published: December 12, 2018 
However, the mechanisms involved in the neuroprotective effects of rosiglitazone are not fully elucidated.

Therefore, we aimed to evaluate the efficacy of rosiglitazone in the behavioral alterations induced by LPS activation of the immune system. Besides, we evaluated whether rosiglitazone actions would be related to modulation of TNF- $\alpha$ expression, decrease in oxidative stress parameters and normalization of BDNF levels in the hippocampus of LPS treated mice.

\section{Methods}

\section{Subjects}

Female adult Swiss albino mice (30-40 g) were kept on a 12-h light/ dark cycle (lights on at 07.00 a.m.) at a temperature of $22 \pm 1^{\circ} \mathrm{C}$. Mice were obtained from the Central Animal Facility of the Universidade Federal de Mato Grosso. They were housed in plastic cages with tap water and commercial food ad libitum. All procedures were carried out according to the institutional policies on animal experimental handling, designed to minimize suffering and limit the number of animals used and were approved by local Ethical Committee for Animal Research (CEUA/UFMT, protocol number: 23108.098456/2015-93).

\section{Reagents}

Lipopolysaccharide from Escherichia coli (strain 055:B5), rosiglitazone, reduced glutathione and bovine serum albumin were purchased from Sigma (St. Louis, MO, USA). TNF- $\alpha$ immunoassay kits were purchased from BD Biosciences (BD Biosciences Laboratory Ltd. USA). The ELISA kit for the measurement of BDNF was purchased from Promega (Madison, WI, USA). All other chemicals were of analytical grade and were purchased from standard commercial suppliers.

\section{Experimental design and treatments}

Mice were treated with the vehicle (saline, $0.9 \%$, p.o) or rosiglitazone ( $5 \mathrm{mg} / \mathrm{kg}$, p.o.). The dose of rosiglitazone used was chosen based on previous studies [19,21]. LPS was dissolved in sterile saline. One hour after rosiglitazone administration, mice were injected with saline or LPS $(0.5 \mathrm{mg} / \mathrm{kg}$, i.p.). The dose of LPS was chosen based on previous studies $[10,22]$. All solutions were freshly prepared on the day of injection and administered at a volume of $10 \mathrm{ml} / \mathrm{kg}$ of body weight. Twenty-four hours after LPS or saline treatment, mice were submitted to behavioral tests. For biochemical analysis, mice were euthanized by decapitation, brains were rapidly removed, the hippocampi isolated and were used for neurochemical assays.

\section{Forced swimming test (FST)}

For the FST, mice were individually forced to swim in an open cylindrical container (diameter $10 \mathrm{~cm}$, height $25 \mathrm{~cm}$ ), containing 19 $\mathrm{cm}$ of water (depth) at $25 \pm 1^{\circ} \mathrm{C}$; the total amount of time each animal remained immobile during a 6 -min session was recorded (in seconds) as immobility time [23]. Each mouse was judged immobile when it ceased struggling and remained floating motionless in the water, making only those movements necessary to keep its head above water. A decrease in the duration of immobility is indicative of an antidepressant-like effect [24].

\section{Tail suspension test (TST)}

The total duration of immobility induced by tail suspension was measured according to the method previously described [25]. Mice that were both acoustically and visually isolated were suspended $50 \mathrm{~cm}$ above the floor by adhesive tape placed approximately $1 \mathrm{~cm}$ from the tip of the tail. Immobility time was recorded during a 6-min period. Mice were considered immobile only when they hung passively or stayed motionless. Conventional antidepressants decrease the immobility time in this test [25].

\section{Open field test (OFT)}

Measurement of locomotor activity in the OFT was performed as previously described [26]. The apparatus consisted of a wooden arena $(30 \times 30 \times 15 \mathrm{~cm})$ with the floor divided in nine equal squares. The experiments were conducted in a sound-attenuated room and light intensity in the centre of the apparatus was $110 \mathrm{~lx}$. Mice were placed in the center of the open field and the number of squares crossed by each mouse with its four paws for $5 \mathrm{~min}$ was considered as indicative of locomotor activity. The arena floor was cleaned with a $70 \%$ ethanol solution between the trials.

\section{Y-maze task}

Spontaneous alternation, which is a measure of spatial working memory, was assessed in the Y-maze task. The Y-maze apparatus consisted of a three-arm horizontal maze with equal angles between all arms. Each arm was $30 \mathrm{~cm}$ length and $5 \mathrm{~cm}$ width, with walls 12 $\mathrm{cm}$ high and converged in an equilateral triangular central area. Each mouse was placed at the end of one arm and allowed to freely move through the maze for $8 \mathrm{~min}$. The sequence and number of arm entries were recorded manually. Entry was considered to be completed when the hind paws of the mouse had been completely placed in the arm. An alternation was defined as entries in all three arms on consecutive occasions. The percentage of alternation was determined by dividing the total number of alternations by the total number of choices minus 2 multiplied by 100 as shown in the following equation: $\%$ Alternation = [(Number of alternations) / (Total arm entries -2$)] \times 100$. The number of arm entries serves as an indicator of locomotor activity [27]. The apparatus was cleaned with a $70 \%$ ethanol solution between each trial.

\section{Step-down inhibitory avoidance (IA) task}

The step-down inhibitory avoidance apparatus consisted of a 50-cm $\times 25-\mathrm{cm} \times 25-\mathrm{cm}$ acrylic box with the front and superior wall made of transparent acrylic. The apparatus floor consisted of a grid of parallel stainless-steel bars of $1 \mathrm{~mm}$ diameter spaced $1 \mathrm{~cm}$ apart. A $22 \times 5-\mathrm{cm}$ wide, $2-\mathrm{cm}$ high acrylic platform was placed in the left end of the box floor. Mice were placed on the platform facing the left corner of the training box, and their latency to step down on the grid with all four paws was measured. Mice were submitted to the IA task using a protocol similar to that described previously [28]. During the training session, immediately after stepping down on the grid, the animals received a scrambled foot shock ( $0.5 \mathrm{~mA}$ for $2 \mathrm{~s}$ ) and were then removed from the box. Test sessions were performed $24 \mathrm{~h}$ after the training. Test sessions were procedurally identical to training session except that no foot shock was given and the step-down latency (maximum $180 \mathrm{~s}$ ) was used as a measure of retention. The measure of memory retention of this test consists of delay of the latency to step-down in test session when compared to the training session.

\section{Non-protein thiol groups (NPSH) determination}

Hippocampi were dissected and homogenized $(1: 10 \mathrm{w} / \mathrm{v})$ in phosphate buffer $(50 \mathrm{mM}, \mathrm{pH}$ 7.4). Homogenates were centrifuged at $1000 \mathrm{~g}$ for $10 \mathrm{~min}$ at $4^{\circ} \mathrm{C}$ to discard nuclei and cell debris. NPSH was determined as previously described [29] with slight modifications. NPSH compounds were measured in an aliquot $(60 \mu \mathrm{l})$ of hippocampal 
homogenates after protein precipitation with one volume of $10 \%$ trichloroacetic acid. After centrifugation $\left(10,000 \mathrm{~g}\right.$ for $10 \mathrm{~min}$ at $\left.4^{\circ} \mathrm{C}\right)$, samples were added to $800 \mathrm{mM}$ phosphate buffer, $\mathrm{pH} 7.4$, and $500 \mu \mathrm{M}$ 5,50-dithiobis-2-nitrobenzoic acid. Color development resulting from the reaction between 5,50-dithio-bis-2-nitrobenzoic acid and thiols reached a maximum in $5 \mathrm{~min}$ and it was stable for more than $30 \mathrm{~min}$. Absorbance was read at $412 \mathrm{~nm}$ after $10 \mathrm{~min}$. A standard curve of reduced glutathione (GSH) was used to calculate NPSH concentrations in samples and the results were expressed as nmol NPSH/mg protein.

\section{Determination of thiobarbituric acid reactive substances (TBARS)}

Thiobarbituric acid reactive substances were determined in tissue homogenates as previously described [30], in which malondialdehyde (MDA), a product of lipid peroxidation, reacts with TBA to form a colored complex. In brief, an aliquot $(100 \mu \mathrm{l})$ of tissue homogenates supernatant was collected and incubated at $100^{\circ} \mathrm{C}$ for $60 \mathrm{~min}$ in acid medium containing $0.45 \%$ sodium dodecyl sulfate and $0.6 \%$ TBA. After centrifugation $\left(10,000 \mathrm{~g}\right.$ for $10 \mathrm{~min}$ at $\left.20^{\circ} \mathrm{C}\right)$, the reaction product was determined at $532 \mathrm{~nm}$ using 1,1,3,3-tetramethoxypropane as the standard, and the results were expressed as nmol MDA/mg protein.

\section{Estimation of TNF- $\alpha$ and BDNF levels}

The hippocampi were homogenized in ten volumes of phosphatebuffered saline (PBS) buffer with protease and phosphatase inhibitors (Sigma-Aldrich) and centrifuged at $4,000 \mathrm{rpm}$ for $20 \mathrm{~min}$. The concentration of TNF- $\alpha$ and BDNF in $50 \mu$ samples was determined by the Enzyme-Linked Immunosorbent Assay (ELISA), according to the manufacturer's instructions. The sample values were then read from the standard curve. TNF- $\alpha$ and BDNF levels were expressed in pg/g tissue and $\mathrm{ng} / \mathrm{g}$ tissue, respectively.

\section{Measurement of protein content}

Protein content was evaluated by the method of Lowry [31]. Bovine serum albumin was used as standard.

\section{Statistical analysis}

Data were expressed as mean \pm S.E.M. Comparisons among groups were performed by one-way analysis of variance (ANOVA) followed by Newman-Keuls's post hoc test when appropriate. Data obtained in IA task were expressed as medians and interquartile range and were analysed by the Kruskal-Wallis test. Comparisons between groups were determined by Mann-Whitney $U$ tests (two-tailed). P values of less than 0.05 were regarded as statistically significant.

\section{Results}

\section{Rosiglitazone prevents LPS-induced depressive-like behavior}

One-way ANOVA revealed the main effect in the duration of immobility time in the TST $[\mathrm{F}(3,24)=11.76, P<0.01]$. Post-hoc analysis indicated that LPS administration promoted a significant increase in the duration of immobility in the TST as compared to control group $(P<0.01)$ and this effect was prevented by rosiglitazone treatment $(P<0.05)$ (Figure 1A). In the FST, one-way ANOVA also revealed statistically significant alteration in the duration of immobility $[F(3,31)=6.85, P<0.01]$ (Figure 1B). Newman-Keuls post-hoc test revealed that LPS administration increased immobility duration as compared to the control group $(P<0.01)$. Rosiglitazone treatment prevented the increase in immobility time induced by LPS injection $(P<0.01)$ in the FST.

\section{Rosiglitazone prevents LPS-induced cognitive deficits}

Spatial working memory, as evaluated by the Y-maze test, revealed that LPS-treated mice presented a significant reduction in the percentage of correct alternations as compared to the control group $\mathrm{F}(3,27)=5.73, P<0.01$ ] (Figure 2 ). Whereas, administration of rosiglitazone significantly prevented the alterations induced by LPS injection $(P<0.01)$ (Figure 2).

Long-term memory was evaluated in the IA task. There were no significant differences in the step-down latencies during the training session across all groups $(P=0.67)$ (Figure 3$)$. LPS administration significantly decrease the step-down latency when compared to the control group in the test session $(P<0.05)$ (Figure 3$)$, suggesting that LPS treatment promoted an impairment of aversive memory. The administration of rosiglitazone significantly prevented the LPS induced a decrease in the latency to step-down in the test session $(P<0.05)$ (Figure 3).

\section{Effects of rosiglitazone or LPS on locomotors activity}

No significant difference was found among groups in the number of crossings in the $\mathrm{OFT}[\mathrm{F}(3,31)=0.35, P=0.78]$ (Figure 4). These data indicated that treatment with rosiglitazone or LPS did not alter locomotor activity.

\section{Effects of rosiglitazone on TNF-a levels in the hippocampus}

LPS injection promoted an increase in hippocampal levels of TNF- $\alpha$ as compared to control group $[\mathrm{F}(3,26)=27.58, P<0.01]$. Rosiglitazone treatment significantly prevented the LPS-induced increase in TNF- $\alpha$ levels $(P<0.01)$ (Figure 5).
A

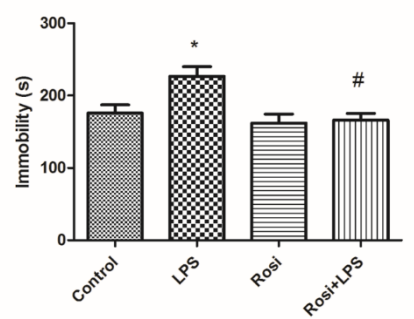

B

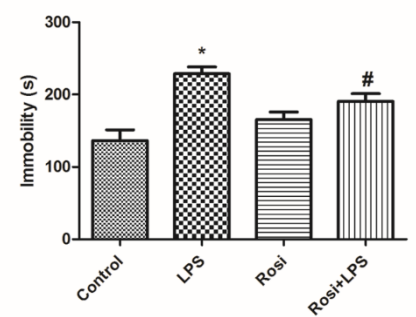

Figure 1. Effect of rosiglitazone treatment on behavioral alterations in the FST and TST promoted by Lipopolysaccharide (LPS) in mice. Mice ( $\mathrm{n}=7-9$ mice/group) were treated with vehicle (saline $0.9 \%$, v.o., Control group) or rosiglitazone $(5 \mathrm{mg} / \mathrm{kg}$, v.o., rosi group) $60 \mathrm{~min}$ before LPS administration $(0.5 \mathrm{mg} / \mathrm{kg}$, i.p.). After $24 \mathrm{~h}$ of LPS injection, mice were subjected to behavioral test immobility time in the FST (A) and TST(B) The values represent mean \pm SEM. * means significantly different from control group. \# means significantly different from LPS group. $\mathrm{P}<0.05$ (ANOVA followed by Newman-Keuls)

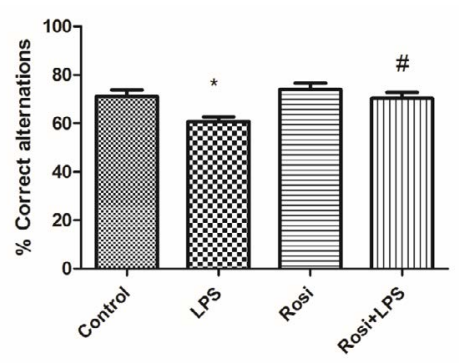

Figure 2. Effect of rosiglitazone treatment on behavioral alterations promoted by Lipopolysaccharide (LPS) in the Y-maze Test. The values represent mean \pm SEM ( $n=7-8$ mice/group). * means significantly different from the control group. \# means significantly different from the LPS group. $\mathrm{P}<0.05$ (ANOVA followed by Newman-Keuls) 


\section{Effects of rosiglitazone on oxidative stress parameters in the hippocampus}

Figures $6 \mathrm{~A}$ and $6 \mathrm{~B}$ show the effects of rosiglitazone on LPS-induced alterations on oxidative stress parameters. LPS administration promoted a decrease in hippocampal GSH levels $[\mathrm{F}(3,27)=4.52, P<0.05]$ in comparison to control group, while rosiglitazone treatment prevented this effect $(P<0.05)$ (Figure 6A). ANOVA demonstrated significant alterations in the MDA levels among the groups $[\mathrm{F}(3,27)=4.56, P<0.05]$. Post-hoc analysis demonstrated that LPS injection induced an increase in the MDA levels in comparison to the control group $(P<0.05)$ and that rosiglitazone treatment prevented this elevation $(P<0.01)$ (Figure 6B).

\section{Effects of rosiglitazone on BDNF levels in the hippocampus}

LPS administration significantly reduced the hippocampal BDNF level as compared to the control group $[\mathrm{F}(3,26)=11.43, P<0.01]$. Rosiglitazone treatment significantly prevented the reduction in the BDNF level in the hippocampus induced by LPS $(P<0.01)$ (Figure 7$)$.

\section{Discussion}

It has been shown that cytokines produced during activation of the immune system affect the behavior of humans and rodents. In the present study, we aimed to evaluate if activation of PPAR- $\gamma$ would attenuate the behavioral and neurochemical alterations promoted by immune system activation following LPS administration in mice. Here, we observed that PPAR- $\gamma$ agonist, rosiglitazone, ameliorated depressive-like behavior and memory impairments induced by systemic LPS administration. Of note, rosiglitazone attenuated LPS-induced

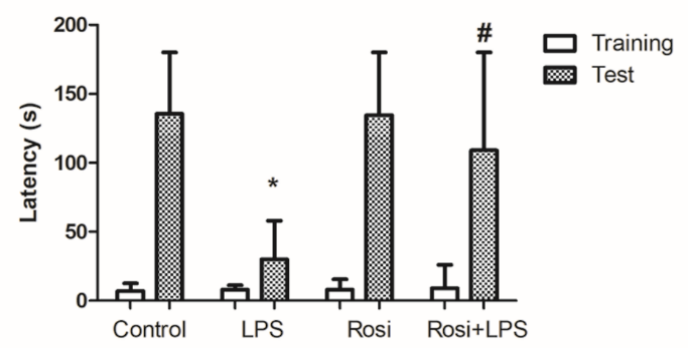

Figure 3. Effect of rosiglitazone treatment on behavioral alterations promoted by Lipopolysaccharide (LPS) in the Inhibitory Avoidance Task. The values represent median and interquartile ranges of latencies to step-down in the training and test sessions $(\mathrm{n}=10-12$ mice/group). * means significantly different from control group during the test session. \# means significantly different from LPS group during the test session. $\mathrm{P}<0.05$ (KruskalWallis test)

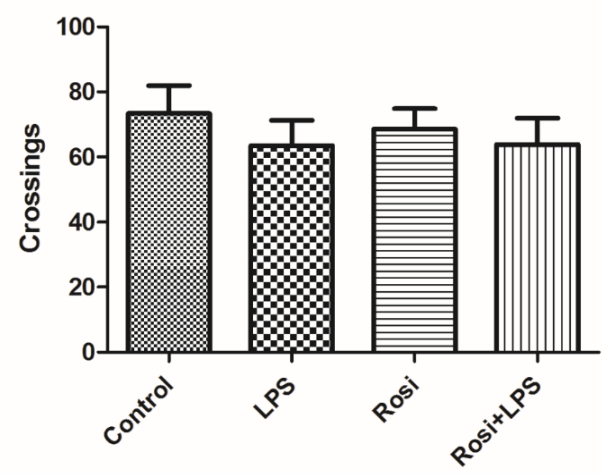

Figure 4. Effect of rosiglitazone treatment in the OFT in mice challenged with LPS. The values represent mean \pm SEM. $\mathrm{N}=8$ mice/group. (One-way ANOVA)

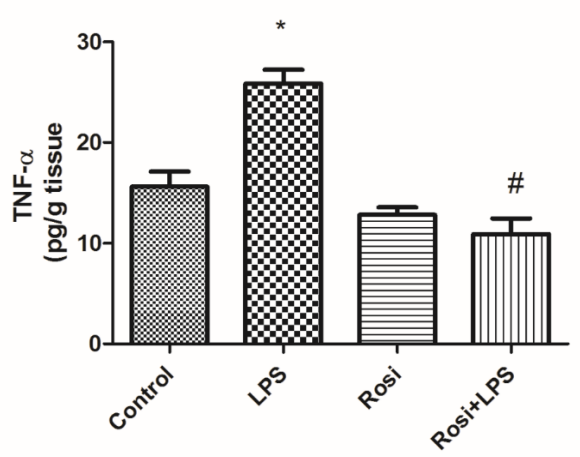

Figure 5. Effect of rosiglitazone treatment on lipopolysaccharide (LPS)-induced increase in hippocampal levels of tumor necrosis factor- $\alpha$ (TNF- $\alpha)$. The values represent mean \pm SEM ( $\mathrm{n}=7-8$ mice/group). * means significantly different from control group. \# means significantly different from LPS group. $\mathrm{P}<0.05$ (ANOVA followed by Newman-Keuls)
A

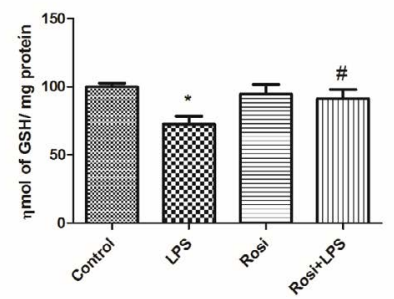

B

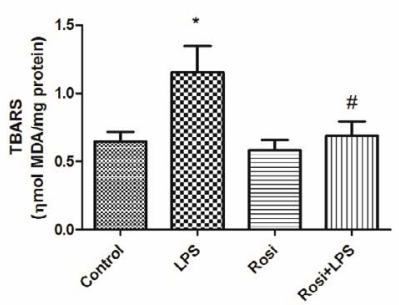

Figure 6. Effect of rosiglitazone treatment on LPS induced oxidative stress in the hippocampus: (A) reduced glutathione (GSH) levels and (B) thiobarbituric acid reactive substances (TBARS) content. The values represent mean \pm SEM. $\mathrm{N}=7-9$ mice per group. * means significantly different from control group. \# means significantly different from the LPS group. $\mathrm{P}<0.05$ (ANOVA followed by Newman-Keuls)

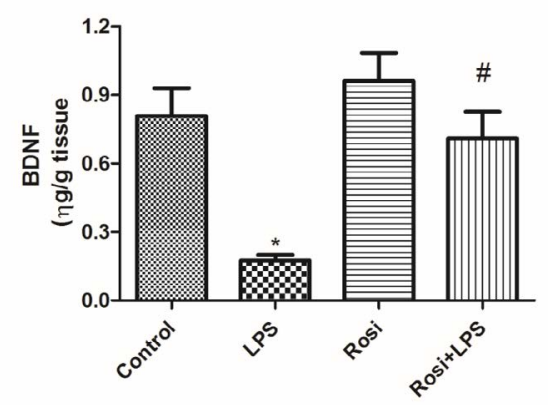

Figure 7. Effect of rosiglitazone treatment on lipopolysaccharide (LPS)-induced decrease in hippocampal levels of brain-derived neurotrophic factor (BDNF) in mice. The values represent mean \pm SEM ( $\mathrm{n}=7-8$ mice/group). * means significantly different from control group. \# means significantly different from the LPS group. $\mathrm{P}<0.05$ (ANOVA followed by Newman-Keuls)

increase in TNF- $\alpha$ level, oxidative stress and restored the decrease in BDNF levels.

Neuroinflammation has been intimately associated with depression pathogenesis [32]. In preclinical studies, the cytokine inducer LPS has been demonstrated to promote behavioral alterations in mice, some of which, resemble depressive symptoms in humans [33]. Using two validated depression tests in rodents, the FST and the TST, we observed that LPS administration increased immobility time indicating an increase in depressive-like behavior, which is in agreement with previous studies $[34,35]$. Apart from the classical depressive symptoms, evidence indicates that depressed patients also display cognitive impairment [36]. In this vein, elevated levels of pro-inflammatory cytokines in the brain, 
besides exacerbating depressive-like behavior, have been shown to result in cognitive deficits in rodents [37]. In the current study, working memory and long-term memory were evaluated in the Y-maze and IA tasks, respectively. In the Y-maze test, LPS injection induced a decrease in the percentage of correct alternations indicating an impairment of spatial working memory. This is in agreement with previous studies that have demonstrated that LPS injection can impair mice and rat's performance in the Y-maze task [38-40]. In the IA task, LPS induced a decrease in the latency to step-down in the test session that indicates an impairment of IA learning. Since the test session was conducted $24 \mathrm{~h}$ after the training session, it may represent a long-term memory impairment. In addition, it has been demonstrated that LPS can impair long-term memory in other behavioral tests such as the step-through and water maze tasks [41,42].

In this study, rosiglitazone prevented depressive-like behavior in the TST and FST induced by systemic LPS administration. In agreement with our results, it has been demonstrated that pioglitazone, another PPAR- $\gamma$ agonist, improved the depressive-like behavior induced by central administration of LPS [43]. Moreover, rosiglitazone has been shown to exert antidepressant-like effects in other rodent models of depression. Zhao and cols [19] have demonstrated that rosiglitazone treatment attenuated depressive-like behavior induced by unpredictable chronic mild stress [19]. Besides, rosiglitazone ameliorated chronic restraint stress or neuropathic pain induced depressive-like behavior $[44,45]$. Interestingly, PPAR- $\gamma$ agonists treatment alone or in combination with conventional treatments have been shown to improve depressive scores in human patients [46]. Beyond preventing LPS-induced depressive-like behavior, we observed that rosiglitazone also attenuated LPS-induced memory impairments in the Y-maze and IA tasks. In agreement with our results, previous reports have shown that PPAR- $\gamma$ agonists improved the cognitive deficits in the Morris water maze and passive avoidance induced by A $\beta 42$ [47], 1-methyl4-phenyl-1,2,3,6-tetrahydropyridine (MPTP) (Kumar et al. 2009) or streptozotocin [48]. Furthermore, rosiglitazone has been shown to prevent LPS-induced spatial memory impairment [49]. In this referred study, memory evaluation was performed at four weeks after LPS injection, a period after the cessation of the depressive symptoms [49]. Importantly, as there was no significant statistical difference in the number of crossings in the OFT, the behavioral alterations promoted by LPS and the protective effects of rosiglitazone in our findings cannot be related to alterations in locomotor activity of the mice.

Clinical studies demonstrated that depressed patients display elevated levels of TNF- $\alpha$ which may be related to the development of depressive symptoms and cognitive decline observed in these patients $[7,50,51]$. In accordance to this, preclinical studies demonstrated that TNF- $\alpha$ administration to rodents exacerbate depressive-like behavior and blockade of TNF- $\alpha$ receptors exerts antidepressant and procognitive effects $[50,52,53]$. In our findings, rosiglitazone prevented the LPS-induced increase in TNF- $\alpha$ level in the hippocampus. In a similar manner, previous studies associated rosiglitazone neuroprotective effects to the attenuation in the increase in TNF- $\alpha$ level in the rodent models of neuropsychiatric disorders [54,55]. Increased levels of TNF- $\alpha$ may be caused by activation of NF- $\kappa B$ in microglia [56]. In fact, it has been demonstrated that PPAR- $\gamma$ activation may exert antiinflammatory actions through inhibition of NF- $\kappa B$ signalling, which may prevent the expression of pro-inflammatory cytokine [43,57]. Taken together, it may be suggested that antidepressant-like effects of rosilgitazone is related to reduction of TNF- $\alpha$ levels in LPS treated mice.

LPS induced the expression of pro-inflammatory cytokines and activation of microglia may promote an increase in the production of reactive oxygen (ROS) species [58]. This may cause deleterious effects to the brain since it is highly vulnerable to oxidative damage [59]. This vulnerability arises from a high production of ROS due to its elevated aerobic metabolic activity, lower antioxidant defences and high content of polyunsaturated fatty acids, which may undergo peroxidation [59]. In the present study, we observed that LPS administration induced an increase in MDA levels and a decrease in GSH levels in the hippocampus. These alterations may contribute to LPS induced behavioral alterations as compounds with antioxidant actions have been shown to prevent LPS induced depressive-like behavior $[10,11,60]$ or memory impairments [61-63]. In our study, rosiglitazone treatment ameliorated LPS-induced reduction of antioxidant status in the hippocampus. Our results are in line with previous reports, which demonstrated that the neuroprotective effects of PPAR- $\gamma$ agonists might be related to the prevention of increased MDA levels and reduction of GSH levels in the brain [6466]. In humans, the increased levels of MDA and decreased levels of GSH have been associated with depressive symptoms and cognitive decline [67-69]. In this way, rosiglitazone prevention of depressive-like behavior and cognitive deficits may be related to the reduction of LPS induced oxidative stress.

Growing pieces of evidence suggest that neurogenesis and neuronal plasticity are compromised in major depression [70]. Lower BDNF levels have been observed in people with depression [71] and it is known that antidepressant treatment increases BDNF level in depressed patients [72-74]. Furthermore, BDNF is required for memory consolidation [75], and that cognitive deficits found in depressive disorders may be related to the decrease in BDNF levels [76]. In rodents, neuroinflammation caused by LPS exposure has been shown to decrease hippocampal BDNF expression [77]. Moreover, the decrease in BDNF levels has been implicated in the depressive-like behavior and memory deficits observed after LPS administration in rodents [78-80]. Here, we observed that rosiglitazone administration prevented LPS-induced decrease in BDNF levels in the hippocampus. This is in agreement with a recent study where pioglitazone prevented the alterations in CREB/BDNF signalling pathway induced by central administration of LPS [43]. Besides, rosiglitazone has been shown to prevent the decrease in BDNF levels in the neuropathic pain model of depression [45] and to increase the expression of BDNF in a diabetes model of cognitive deficits [81].

\section{Conclusions}

In conclusion, these findings demonstrated that rosiglitazone treatment ameliorated LPS-induced depressive-like behavior and memory impairment in mice. Rosiglitazone attenuated LPS-induced neuroinflammation and oxidative stress in mice brain. Besides, rosiglitazone treatment prevented the reduction of BDNF levels in the hippocampus. Taking together, these findings demonstrate a potential role of rosiglitazone in the treatment of depressive and cognitive deficits following neuroinflammation.

\section{Acknowledgements}

This work was supported by Fundação de Amparo à Pesquisa do Estado de Mato Grosso (FAPEMAT), process number 222343/2015.

\section{Conflicts of Interest}

The authors declare that they have no conflicts of interest.

\section{References}

1. Taciak PP, Lysenko N, Mazurek AP (2017) Drugs which influence serotonin transporter and serotonergic receptors: Pharmacological and clinical properties in the treatment of depression. Pharmacol Rep 70: 37-46. [Crossref] 
2. Misztak P, Panczyszyn-Trzewik P, Sowa-Kucma M (2018) Histone deacetylases (HDACs) as therapeutic target for depressive disorders. Pharmacol Rep 70: 398-408. [Crossref]

3. Patel TK, Patel VB, Rana DG (2017) Possible anti-depressant effect of efavirenz and pro-depressive-like effect of voriconazole in specified doses in various experimental models of depression in mice. Pharmacol Rep 69: 1082-1087. [Crossref]

4. Willner P, Scheel-Kruger J, Belzung C (2013) The neurobiology of depression and antidepressant action. Neurosci Biobehav Rev 37: 2331-2371. [Crossref]

5. Lason W, Budziszewska B, Basta-Kaim A, Kubera M, Maes M (2013) New trends in the neurobiology and pharmacology of affective disorders. Pharmacol Rep 65: 14411450. [Crossref]

6. Ma L, Demin KA, Kolesnikova TO, Khatsko SL, Zhu X, et al. (2017) Anima inflammation-based models of depression and their application to drug discovery. Expert Opin Drug Discov 12: 995-1009. [Crossref]

7. Dowlati Y, Herrmann N, Swardfager W, Liu H, Sham L, et al. (2010) A meta-analysis of cytokines in major depression. Biol Psychiatry 67: 446-457. [Crossref]

8. Dantzer R, O'Connor JC, Freund GG, Johnson RW, Kelley KW (2008) From inflammation to sickness and depression: when the immune system subjugates the brain. Nat Rev Neurosci 9: 46-56. [Crossref]

9. Lee JW, Lee YK, Yuk DY, Choi DY, Ban SB, et al. (2008) Neuro-inflammation induced by lipopolysaccharide causes cognitive impairment through enhancement of betaamyloid generation. J Neuroinflammation 5: 37. [Crossref]

10. Taniguti EH, Ferreira YS, Stupp IJV, Fraga-Junior EB, Mendonça CB, et al. (2018) Neuroprotective effect of melatonin against lipopolysaccharide-induced depressivelike behavior in mice. Physiol Behav 188: 270-275. [Crossref]

11. Zhu L, Nang C, Luo F, Pan H, Zhang K, et al. (2016) Esculetin attenuates lipopolysaccharide (LPS)-induced neuroinflammatory processes and depressive-like behavior in mice. Physiol Behav 163: 184-192. [Crossref]

12. Adebesin A, Adeoluwa OA, Eduviere AT, Umukoro S (2017) Methyl jasmonate attenuated lipopolysaccharide-induced depressive-like behaviour in mice. $J$ Psychiatr Res 94: 29-35. [Crossref]

13. Khallaf WAI, Messiha BAS, Abo-Youssef AMH, El-Sayed NS (2017) Protective effects of telmisartan and tempol on lipopolysaccharide-induced cognitive impairment, neuroinflammation, and amyloidogenesis: possible role of brain-derived neurotrophic factor. Can J Physiol Pharmacol 95: 850-860. [Crossref]

14. Heikkinen S, Auwerx J, Argmann CA (2007) PPARgamma in human and mouse physiology. Biochim Biophys Acta 1771: 999-1013. [Crossref]

15. Nanjan MJ, Mohammed M, Prashantha Kumar BR, Chandrasekar MJN (2018) Thiazolidinediones as antidiabetic agents: A critical review. Bioorg Chem 77: 548-567. [Crossref]

16. Bordet R, Ouk T, Petrault O, Gelé P, Gautier S, et al. (2006) PPAR: a new pharmacological target for neuroprotection in stroke and neurodegenerative diseases. Biochem Soc Trans 34: 1341-1346. [Crossref]

17. Yao J, Zheng K, Zhang X (2015) Rosiglitazone exerts neuroprotective effects via the suppression of neuronal autophagy and apoptosis in the cortex following traumatic brain injury. Mol Med Rep 12: 6591-6597. [Crossref]

18. Eissa Ahmed AA, Al-Rasheed NM, Al-Rasheed NM (2009) Antidepressant-like effects of rosiglitazone, a PPARgamma agonist, in the rat forced swim and mouse tail suspension tests. Behav Pharmacol 20: 635-642. [Crossref]

19. Zhao Z, Zhang L, Guo XD, Cao LL, Xue TF, et al. (2017) Rosiglitazone Exerts an Anti-depressive Effect in Unpredictable Chronic Mild-Stress-Induced Depressive Mice by Maintaining Essential Neuron Autophagy and Inhibiting Excessive Astrocytic Apoptosis. Front Mol Neurosci 10: 293. [Crossref]

20. Mandrekar-Colucci S, Sauerbeck A, Popovich PG, McTigue DM (2013) PPAR agonists as therapeutics for CNS trauma and neurological diseases. ASN Neuro 5: e00129. [Crossref]

21. Buss Zda S, Medeiros YS, Frode TS (2012) PPAR-gamma agonist rosiglitazone attenuates the inflammation caused by carrageenan in the mouse model of pleurisy. Inflammation 35: 280-288. [Crossref]

22. Mello BS, Monte AS, McIntyre RS, Soczynska JK, Custódio CS, et al. (2013) Effects of doxycycline on depressive-like behavior in mice after lipopolysaccharide (LPS) administration. J Psychiatr Res 47: 1521-1529. [Crossref]

23. Brocardo Pde S, Budni J, Lobato KR, Kaster MP, Rodrigues AL (2008) Antidepressantlike effect of folic acid: Involvement of NMDA receptors and L-arginine-nitric oxidecyclic guanosine monophosphate pathway. Eur J Pharmacol 598: 37-42. [Crossref]
24. Porsolt RD, Bertin A, Jalfre M (1977) Behavioral despair in mice: a primary screening test for antidepressants. Arch Int Pharmacodyn Ther 229: 327-336. [Crossref]

25. Steru L, Chermat R, Thierry B, Simon P (1985) The tail suspension test: a new method for screening antidepressants in mice. Psychopharmacology (Berl) 85: 367-370. [Crossref]

26. Vandresen-Filho S, França LM, Alcantara-Junior J, Nogueira LC, de Brito TM, et al (2015a) Statins enhance cognitive performance in object location test in albino Swiss mice: involvement of beta-adrenoceptors. Physiol Behav 143: 27-34. [Crossref]

27. Kim DH, Moore DH, Makriyannis A, Abood ME (2006) AM1241, a cannabinoid CB2 receptor selective compound, delays disease progression in a mouse model of amyotrophic lateral sclerosis. Eur J Pharmacol 542: 129-135. [Crossref]

28. Lucena GM, Prediger RD, Silva MV, Santos SN, Silva JF, et al. (2013) Ethanolic extract from bulbs of Cipura paludosa reduced long-lasting learning and memory deficits induced by prenatal methylmercury exposure in rats. Dev Cogn Neurosci 3 : 1-10. [Crossref]

29. Ellman GL (1959) Tissue sulfhydryl groups. Arch Biochem Biophys 82: 70-77. [Crossref]

30. Vandresen-Filho S, Martins WC, Bertoldo DB, Mancini G, De Bem AF, et al. (2015b) Cerebral cortex, hippocampus, striatum and cerebellum show differential susceptibility to quinolinic acid-induced oxidative stress. Neurol Sci 36: 1449-1456. [Crossref]

31. Lowry OH, Rosebrough NJ, Farr AL, Randall RJ (1951) Protein measurement with the Folin phenol reagent. J Biol Chem 193: 265-275. [Crossref]

32. Kim YK, Na KS, Myint AM, Leonard BE (2016) The role of pro-inflammatory cytokines in neuroinflammation, neurogenesis and the neuroendocrine system in major depression. Prog Neuropsychopharmacol Biol Psychiatry 64: 277-284. [Crossref]

33. Dantzer R (2009) Cytokine, sickness behavior, and depression. Immunol Allergy Clin North Am 29: 247-264. [Crossref]

34. Mousavi SE, Saberi P, Ghasemkhani N, Fakhraei N, Mokhtari R, et al. (2018) Licofelone Attenuates LPS-induced Depressive-like Behavior in Mice: A Possible Role for Nitric Oxide. J Pharm Pharm Sci 21: 184-194. [Crossref]

35. Yamawaki Y, Yoshioka N, Nozaki K, Ito H, Oda K, et al. (2018) Sodium butyrate abolishes lipopolysaccharide-induced depression-like behaviors and hippocampal microglial activation in mice. Brain Res 1680: 13-38. [Crossref]

36. Lima IMM, Peckham AD, Johnson SL (2018) Cognitive deficits in bipolar disorders: Implications for emotion. Clin Psychol Rev 59: 126-136. [Crossref]

37. Caraci F, Spampinato SF, Morgese MG, Tascedda F, Salluzzo MG, et al. (2018) Neurobiological links between depression and AD: The role of TGF-betal signaling as a new pharmacological target. Pharmacol Res 130: 374-384. [Crossref]

38. Khajevand-Khazaei MR, Ziaee P, Motevalizadeh SA, Rohani M, Afshin-Majd S, et al. (2018) Naringenin ameliorates learning and memory impairment following systemic lipopolysaccharide challenge in the rat. Eur J Pharmacol 826: 114-122. [Crossref]

39. Mirahmadi SM, Shahmohammadi A, Rousta AM, Azadi MR, Fahanik-Babaei J, et al. (2018) Soy isoflavone genistein attenuates lipopolysaccharide-induced cognitive impairments in the rat via exerting anti-oxidative and anti-inflammatory effects. Cytokine 104: 151-159. [Crossref]

40. Thabit S, El Sayed NSE (2018) Effect of pioglitazone and simvastatin in lipopolysaccharide-induced amyloidogenesis and cognitive impairment in mice: possible role of glutamatergic pathway and oxidative stress. Behav Pharmacol [Crossref]

41. Dolatabadi HRD, Zarrindast MR, Reisi P, Nasehi M (2017) The Effects of Pentoxifylline on Serum Levels of Interleukin 10 and Interferon Gamma and Memory Function in Lipopolysaccharide-induced Inflammation in Rats. Adv Biomed Res 6: 110. [Crossref]

42. Liu Y, Zhang Y, Zheng X, Fang T, Yang X, et al. (2018) Galantamine improves cognition, hippocampal inflammation, and synaptic plasticity impairments induced by lipopolysaccharide in mice. J Neuroinflammation 15: 112. [Crossref]

43. Liao L, Zhang XD, Li J, Zhang ZW, Yang CC, et al. (2017) Pioglitazone attenuates lipopolysaccharide-induced depression-like behaviors, modulates NF-kappaB/IL-6/ STAT3, CREB/BDNF pathways and central serotonergic neurotransmission in mice. Int Immunopharmacol 49: 178-186. [Crossref]

44. Cheng Y, Rodriguiz RM, Murthy SR, Senatorov V, Thouennon E, et al. (2015) Neurotrophic factor-alpha1 prevents stress-induced depression through enhancement of neurogenesis and is activated by rosiglitazone. Mol Psychiatry 20: 744-754. [Crossref]

45. Zong J, Liao X, Ren B, Wang Z (2018) The antidepressant effects of rosiglitazone on rats with depression induced by neuropathic pain. Life Sci 203: 315-322. [Crossref] 
46. Colle R, de Larminat D, Rotenberg S, Hozer F, Hardy P, et al. (2017) PPAR-gamma Agonists for the Treatment of Major Depression: A Review. Pharmacopsychiatry 50: 49-55. [Crossref]

47. Xu S, Guan Q, Wang C, Wei X, Chen X, et al. (2014) Rosiglitazone prevents the memory deficits induced by amyloid-beta oligomers via inhibition of inflammatory responses. Neurosci Lett 578: 7-11. [Crossref]

48. Liu LP, Yan TH, Jiang LY, Hu W, Hu M, et al. (2013) Pioglitazone ameliorates memory deficits in streptozotocin-induced diabetic mice by reducing brain beta-amyloid through PPAR $\gamma$ activation. Acta Pharmacol Sin 34:455-463. [Crossref]

49. Ormerod BK, Hanft SJ, Asokan A, Haditsch U, Lee SW, et al. (2013) PPARgamma activation prevents impairments in spatial memory and neurogenesis following transient illness. Brain Behav Immun 29: 28-38. [Crossref]

50. Bortolato B, Carvalho AF, Soczynska JK, Perini GI, McIntyre RS (2015) The Involvement of TNF-alpha in Cognitive Dysfunction Associated with Major Depressive Disorder: An Opportunity for Domain Specific Treatments. Curr Neuropharmacol 13: 558-576. [Crossref]

51. Tuglu C, Kara SH, Caliyurt O, Vardar E, Abay E (2003) Increased serum tumor necrosis factor-alpha levels and treatment response in major depressive disorder. Psychopharmacology (Berl) 170: 429-433. [Crossref]

52. Belarbi K, Jopson T, Tweedie D, Arellano C, Luo W, et al. (2012) TNF-alpha protein synthesis inhibitor restores neuronal function and reverses cognitive deficits induced by chronic neuroinflammation. J Neuroinflammation 9: 23. [Crossref]

53. Souza LC, Filho CB, Fabbro LD, de Gomes MG, Goes AT, et al. (2013) Depressive-like behaviour induced by an intracerebroventricular injection of streptozotocin in mice: the protective effect of fluoxetine, antitumour necrosis factor-alpha and thalidomide therapies. Behav Pharmacol 24: 79-86. [Crossref]

54. Garcia-Bueno B, Madrigal JL, Lizasoain I, Moro MA, Lorenzo P, etal. (2005) Peroxisome proliferator-activated receptor gamma activation decreases neuroinflammation in brain after stress in rats. Biol Psychiatry 57: 885-894. [Crossref]

55. Mishra J, Chaudhary T, Kumar A (2014) Rosiglitazone synergizes the neuroprotective effects of valproic acid against quinolinic acid-induced neurotoxicity in rats: targeting PPAR $\gamma$ and HDAC pathways Neurotox Res 26: 130-151. [Crossref]

56. Zhao Q, Wu X, Yan S, Xie X, Fan Y, et al. (2016) The antidepressant-like effects of pioglitazone in a chronic mild stress mouse model are associated with PPARgammamediated alteration of microglial activation phenotypes. J Neuroinflammation 13: 259 . [Crossref]

57. Madeira JM, Schindler SM, Klegeris A (2015) A new look at auranofin, dextromethorphan and rosiglitazone for reduction of glia-mediated inflammation in neurodegenerative diseases. Neural Regen Res 10: 391-393. [Crossref]

58. Kaneko YS, Ota A, Nakashima A, Mori K, Nagatsu I, et al. (2012) Regulation of oxidative stress in long-lived lipopolysaccharide-activated microglia. Clin Exp Pharmacol Physiol 39: 599-607. [Crossref]

59. Patel M (2016) Targeting Oxidative Stress in Central Nervous System Disorders. Trends Pharmacol Sci 37: 768-778. [Crossref]

60. Jangra A, Lukhi MM, Sulakhiya K, Baruah CC, Lahkar M (2014) Protective effect of mangiferin against lipopolysaccharide-induced depressive and anxiety-like behaviour in mice. Eur J Pharmacol 740: 337-345. [Crossref]

61. Chowdhury AA, Gawali NB, Shinde P, Munshi R, Juvekar AR (2018) Imperatorin ameliorates lipopolysaccharide induced memory deficit by mitigating proinflammatory cytokines, oxidative stress and modulating brain-derived neurotropic factor. Cytokine 110: 78-86. [Crossref]

62. Kim YE, Hwang CJ, Lee HP, Kim CS, Son DJ, et al. (2017) Inhibitory effect of punicalagin on lipopolysaccharide-induced neuroinflammation, oxidative stress and memory impairment via inhibition of nuclear factor-kappaB. Neuropharmacology 117 21-32. [Crossref]

63. Lee YJ, Choi DY, Choi IS, Kim KH, Kim YH, et al. (2012) Inhibitory effect of 4-O-methylhonokiol on lipopolysaccharide-induced neuroinflammation, amyloidogenesis and memory impairment via inhibition of nuclear factor-kappaB in vitro and in vivo models. J Neuroinflammation 9: 35. [Crossref]

64. Kumar P, Kaundal RK, More S, Sharma SS (2009) Beneficial effects of pioglitazone on cognitive impairment in MPTP model of Parkinson's disease. Behav Brain Res 197: 398-403. [Crossref]

65. Sayan-Ozacmak H, Ozacmak VH, Barut F, Jakubowska-Dogru E (2012) Rosiglitazone treatment reduces hippocampal neuronal damage possibly through alleviating oxidative stress in chronic cerebral hypoperfusion. Neurochem Int 61: 287-290. [Crossref]
66. Yu X, Shao XG, Sun H, Li YN, Yang J, et al. (2008) Activation of cerebral peroxisome proliferator-activated receptors gamma exerts neuroprotection by inhibiting oxidative stress following pilocarpine-induced status epilepticus. Brain Res 1200: 146-158. [Crossref]

67. Bajpai A, Verma AK, Srivastava M, Srivastava R (2014) Oxidative stress and major depression. J Clin Diagn Res 8: CC04-07. [Crossref]

68. Hajjar I, Hayek SS, Goldstein FC, Martin G, Jones DP, et al. (2018) Oxidative stres predicts cognitive decline with aging in healthy adults: an observational study. $J$ Neuroinflammation 15: 17. [Crossref]

69. Revel F, Gilbert T, Roche S, Drai J, Blond E, Ecochard R, Bonnefoy M (2015) Influence of oxidative stress biomarkers on cognitive decline. J Alzheimers Dis 45 : 553-560. [Crossref]

70. Lee BH, Kim YK (2010) The roles of BDNF in the pathophysiology of major depression and in antidepressant treatment. Psychiatry Investig 7: 231-235. [Crossref]

71. Kreinin A, Lisson S, Nesher E, Schneider J, Bergman J, et al. (2015) Blood BDNF level is gender specific in severe depression. PLoS One 10: e0127643. [Crossref]

72. Aydemir O, Deveci A, Taneli F (2005) The effect of chronic antidepressant treatment on serum brain-derived neurotrophic factor levels in depressed patients: a preliminary study. Prog Neuropsychopharmacol Biol Psychiatry 29: 261-265. [Crossref]

73. Matrisciano F, Bonaccorso S, Ricciardi A, Scaccianoce S, Panaccione I, et al. (2009) Changes in BDNF serum levels in patients with major depression disorder (MDD) after 6 months treatment with sertraline, escitalopram, or venlafaxine. J Psychiatr Res 43: 247-254. [Crossref]

74. Shimizu E, Hashimoto K, Okamura N, Koike K, Komatsu N, et al (2003) Alteration of serum levels of brain-derived neurotrophic factor (BDNF) in depressed patients with or without antidepressants. Biol Psychiatry 54: 70-75. [Crossref]

75. Rattiner LM, Davis M, French CT, Ressler KJ (2004) Brain-derived neurotrophic factor and tyrosine kinase receptor B involvement in amygdala-dependent fear conditioning. $J$ Neurosci 24: 4796-4806. [Crossref]

76. Amidfar M, Kim YK, Wiborg O (2018) Effectiveness of memantine on depression-like behavior, memory deficits and brain mRNA levels of BDNF and TrkB in rats subjected to repeated unpredictable stress. Pharmacol Rep 70: 600-606. [Crossref]

77. Zhang JC, Wu J, Fujita Y, Yao W, Ren Q, et al. (2014) Antidepressant effects of TrkB ligands on depression-like behavior and dendritic changes in mice after inflammation. Int $J$ Neuropsychopharmacol 18. [Crossref]

78. Fruhauf-Perez PK, Temp FR, Pillat MM, Signor C, Wendel A, et al. (2018) Spermine protects from LPS-induced memory deficit via BDNF and TrkB activation. Neurobiol Learn Mem 149: 135-143. [Crossref]

79. Ge L, Liu L, Liu H, Liu S, Xue H, et al. (2015) Resveratrol abrogates lipopolysaccharideinduced depressive-like behavior, neuroinflammatory response, and CREB/BDNF signaling in mice. Eur J Pharmacol 768: 49-57. [Crossref]

80. Ren Z, Yan P, Zhu L, Yang H, Zhao Y, et al. (2018) Dihydromyricetin exerts a rapid antidepressant-like effect in association with enhancement of BDNF expression and inhibition of neuroinflammation. Psychopharmacology (Berl) 235: 233-244. [Crossref]

81. Kariharan T, Nanayakkara G, Parameshwaran K, Bagasrawala I, Ahuja M, et al. (2015) Central activation of PPAR-gamma ameliorates diabetes induced cognitive dysfunction and improves BDNF expression. Neurobiol Aging 36: 1451-1461. [Crossref]

Copyright: (C2018 Stupp IJV. This is an open-access article distributed under the terms of the Creative Commons Attribution License, which permits unrestricted use, distribution, and reproduction in any medium, provided the original author and source are credited. 